\title{
The Q-Trap Mass Spectrometer, a Novel Tool in the Study of Protein Glycosylation
}

\author{
K. Sandra, B. Devreese, and J. Van Beeumen \\ Laboratory of Protein Biochemistry and Protein Engineering, Ghent University, Ghent, Belgium
}

\section{Stals and M. Claeyssens}

Laboratory of Biochemistry, Ghent University, Ghent, Belgium

\begin{abstract}
The use of the recently introduced Q-Trap mass spectrometer in the study of protein glycosylation is described. The combined ion trap and triple quadrupole scan functions make it a powerful system in both oligosaccharide and glycopeptide analysis. Several oligosaccharides, both linear and branched, were analyzed to obtain information on sequence, linkage, and branching. Quadrupole like MS/MS spectra with ion trap sensitivity but without the typical ion trap low mass cut-off were obtained. To determine the origin of fragments and to reveal the existence of new ions, the $\mathrm{MS}^{3}$ capabilities of the system proved to be useful. Glycopeptides were selectively detected in peptide mixtures using the triple quadrupole precursor ion scan function, either in off-line experiments or during LC/MS using information dependent acquisition (IDA). (J Am Soc Mass Spectrom 2004, 15, 413-423) () 2004 American Society for Mass Spectrometry
\end{abstract}

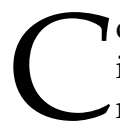
ovalent attachment of carbohydrates to proteins is one of the most common post-translational modifications. The glycans can influence the activity, solubility, and stability of proteins and, as part of membrane proteins, they contribute to cellular communication systems. Modifications in glycosylation have often been associated with diseases such as cancer, rheumatoid arthritis, and prion associated malfunctions. Moreover, the oligosaccharide moieties can have a significant impact on the therapeutic properties of proteins [1-3]. Characterization of glycans is thus of utmost importance. Structural elucidation of glycans is still a challenging task. Unlike other biopolymers, such as proteins and nucleic acids, glycans are usually branched structures and the monomers can be linked together at various positions. In the study of glycans, the constituent monosaccharides, their sequence, branching pattern, and which of the monosaccharide hydroxyl groups is involved in the linkage of one residue to another have to be determined. Mass spectrometry (MS), although it usually cannot differentiate between the different hexoses and hexoseamines, has become a valuable technique in oligosaccharide characterization. Matrix-assisted laser desorption ionization (MALDI) MS is commonly used for oligosaccharide profiling (molecular mass determination) and, in combination with post-source decay (PSD) or collision-

Published online January 29, 2004

Address reprint requests to Dr. J. Van Beeumen, Laboratory of Protein Biochemistry and Protein Engineering, Ghent University, K. L. Ledeganckstraat 35, B-9000 Ghent, Belgium. E-mail: jozef.vanbeeumen@UGent.be induced dissociation (CID), structural information can be obtained [4-8]. Electrospray ionization (ESI) tandem MS became the method of choice to determine structural features such as sequence, linkage and branching [9-11]. Originally, however, ESI-MS of glycans did not match the popularity of MALDI-MS due to sensitivity problems and excessive sample consumption. This situation changed with the introduction of nanospray technology $[12,13]$. The ion trap mass analyzer, with its possibilities to perform multiple stages of fragmentation $\left(\mathrm{MS}^{n}\right)$, is probably the most useful system in carbohydrate structure elucidation [14-17]. In the present study a recently introduced ion trap mass spectrometer, the so-called Q-Trap, is used [18, 19]. The system is a modified triple quadrupole where the Q3 region can be operated either as a conventional quadrupole mass filter or a linear ion trap (LIT) with axial ion ejection. Compared with conventional 3-D ion trap instruments, the volume of the trapping chamber is drastically increased, leading to a larger capacity and less space charging effects, and thus to higher sensitivity. Because precursor ion selection (Q1) and fragmentation (Q2) are de-coupled from the linear ion trap (Q3), triple quadrupole type of fragmentation without low mass cut-off is obtained. The system also has $\mathrm{MS}^{3}$ capabilities which is useful to determine the origin of the fragments. Because of extensive fragmentation in the second quadrupole, there is no need for $\mathrm{MS}^{n}(n>3)$ capabilities. The Q-Trap is equipped with an entrance RF-only quadrupole (Q0) that can be used as an accumulation ion trap while the LIT is scanning. This contributes to improved sensitivity in product ion or 
$\mathrm{MS}^{3}$ scanning. The Q-Trap possesses all of the traditional triple quadrupole scan functions and the precursor ion scan mode is especially powerful to determine glycosylation sites. Combining this precursor ion scan, as a survey scan, in an information dependent acquisition (IDA) experiment with LIT scan functions, as dependent scans, glycopeptides can be identified 'on the fly' during LC/MS. Some examples were selected to illustrate the features of the Q-Trap in the study of glycosylation phenomena.

\section{Experimental}

\section{Materials and Sample Preparation}

Maltoheptaose and bovine pancreas ribonuclease B (RNase B) were obtained from Sigma-Aldrich (St. Louis, $\mathrm{MO})$. Cellobiohydrolase I (CBH I) was produced in house [Stals, I. et al., unpublished]. All other (bio)chemicals, unless noted, were purchased from SigmaAldrich. Glycans were released from the glycoproteins by enzymatic deglycosylation with peptide- $\mathrm{N}$-glycosidase F (PNGase F - Roche Diagnostics GmbH, Mannheim, Germany) or endoglycosidase $\mathrm{H}$ (Endo $\mathrm{H}$ ) according to the method described by Jackson [20]. Ten $\mu$ l of a solution consisting of $1 \%$ sodium dodecylsulfate (SDS), $0.5 \%$ mercaptoethanol, and $0.1 \mathrm{M}$ ethylenediamine tetra acetic acid (EDTA) was added to $1 \mathrm{mg}$ protein. After $30 \mathrm{~min}$ incubation at room temperature, $150 \mu l 200 \mathrm{mM}$ Na-phosphate buffer (pH 8.6) was added and the mixture was placed in a boiling water bath for $5 \mathrm{~min}$. After cooling to room temperature, $10 \mu \mathrm{l}$ of $7.5 \%$ Triton X100 and 2 units of PNGase F or Endo H were added and the mixture was incubated at $37^{\circ} \mathrm{C}$ for $20 \mathrm{~h}$. The $\mathrm{N}$-glycans were purified from the reaction medium by solid phase extraction (SPE) on a Carbograph column (Alltech, Lokeren, Belgium) [21]. The glycans were eluted with $2 \mathrm{ml} 25 \%$ acetonitrile (Biosolve, Valkenswaard, The Netherlands) containing $0.05 \%$ trifluoroacetic acid. After lyophilization the residue was redissolved in $100 \mu \mathrm{l}$ Milli Q water (Millipore, Bedford, MA). For MS, $1 \mu \mathrm{l}$ of this solution was dissolved in $100 \mu \mathrm{l} \mathrm{50 \%}$ methanol (Biosolve, Valkenswaard, The Netherlands).

For permethylation of the oligosaccharides a modification of the procedure described by Ciucanu and Kerek was applied [22]. Five $\mu$ l of the RNase B glycans stock solution was dissolved in $40 \mu \mathrm{l}$ dimethyl sulfoxide (DMSO). Powderous sodium hydroxide (2 $\mathrm{mg}$ ) and 40 $\mu \mathrm{l}$ of cold $\left(5^{\circ} \mathrm{C}\right)$ methyl iodide were added and the mixture was sonicated at $20^{\circ} \mathrm{C}$ during $45 \mathrm{~min}$. The reaction was quenched by drop wise addition of $0.4 \mathrm{ml}$ Milli Q water. The methylated glycans were extracted with chloroform (three times $0.4 \mathrm{ml}$ ). The combined organic phases were rinsed with $0.5 \mathrm{ml}$ Milli $\mathrm{Q}$ water (five times) until clear. The extract was dried under a nitrogen stream and redissolved in $100 \mu \mathrm{l}$ Milli Q water. For MS analysis the solution was diluted 10 times with $50 \%$ methanol.

Maltoheptaose (500 pmol) and the CBH I N-glycans
( $1 \mu \mathrm{l}$ of the stock solution) were derivatized by reductive amination [23]. After drying, $2 \mu \mathrm{l}$ of $100 \mathrm{mM}$ 2-aminobenzoic acid or 3-aminopyrazole in $0.9 \mathrm{M}$ citric acid and $1 \mu \mathrm{l}$ of $1 \mathrm{M} \mathrm{NaBH}_{3} \mathrm{CN}$ (sodium cyanoborohydride) in tetrahydrofuran were added. After incubation at $55^{\circ} \mathrm{C}$ for $2 \mathrm{~h}, 10 \mu \mathrm{l}$ Milli $\mathrm{Q}$ water and $80 \mu \mathrm{l}$ ice-cold acetone were added and the mixture was placed at $-20^{\circ} \mathrm{C}$ for $10 \mathrm{~min}$. The reaction tube was centrifuged at $12,500 \mathrm{rpm}$ for $15 \mathrm{~min}$. The supernatant was removed and the precipitated sugars were redissolved in $100 \mu \mathrm{l}$ $50 \%$ methanol.

For proteolysis, $25 \mu \mathrm{g}$ RNase B was dissolved in 100 $\mu 150 \mathrm{mM}$ ammonium bicarbonate $\left(\mathrm{NH}_{4} \mathrm{HCO}_{3}\right)$ and 0.5 $\mu \mathrm{g}$ modified trypsin (Promega, Madison, WI) was added. The reaction mixture was incubated overnight at $37^{\circ} \mathrm{C}$ and without further purification diluted 10 times in $50 \%$ methanol containing $1 \%$ formic acid (Pancreac, Barcelona, Spain). CBH I was reduced and alkylated prior to proteolyis. The protein $(12 \mu \mathrm{g})$ was dissolved in $300 \mu 150 \mathrm{mM} \mathrm{NH}_{4} \mathrm{HCO}_{3}$ and $20 \mu \mathrm{l} 45 \mathrm{mM}$ dithiothreitol (DTT) was added. Reduction took place at $60^{\circ} \mathrm{C}$ during $30 \mathrm{~min}$. After cooling to room temperature $20 \mu \mathrm{l}$ iodoacetamide $(100 \mathrm{mM})$ was added and the mixture was placed in the dark for $30 \mathrm{~min}$. The reduced and alkylated protein was purified from the reaction medium by membrane filtration using an Ultrafree- 0.5 centrifugal filter (Millipore) with a molecular mass limit of $10 \mathrm{kDa}$. A volume of $150 \mu \mathrm{l} \mathrm{NH} \mathrm{N}_{4} \mathrm{HCO}_{3}(50 \mathrm{mM})$ and $0.2 \mu \mathrm{g}$ trypsin were added and the mixture was incubated at $37^{\circ} \mathrm{C}$ for $4 \mathrm{~h}$. For LC/MS analysis the digest was diluted 3 times in $0.1 \%$ formic acid.

\section{Mass Spectrometry}

MS experiments were performed on a Q-Trap LC/ MS/MS system (Applied Biosystems/MDS Sciex, Concord, ON, Canada) equipped with a nanospray ion source (Protana, Odense, Denmark). The mass range of the instrument is $m / z 5-1700$ in quadrupole mode and $m / z$ 50-1700 in LIT-mode. The latter allows three scan speeds, namely 250, 1000, and $4000 \mathrm{Da} / \mathrm{s}$. Highest sensitivity is obtained at $4000 \mathrm{Da} / \mathrm{s}$ and best resolution at $250 \mathrm{Da} / \mathrm{s}$. In product ion scanning and $\mathrm{MS}^{3}$ the scan speed was set to $4000 \mathrm{Da} / \mathrm{s}$, with Q0-trapping activated. The collision energy and excitation energy were compound dependent. Excitation time was $100 \mathrm{~ms}$. The trap fill-time was $20 \mathrm{~ms}$ in the MS-, $200 \mathrm{~ms}$ in the MS/MSand $300 \mathrm{~ms}$ in the $\mathrm{MS}^{3}$-scan modes. For operation in the MS/MS and $\mathrm{MS}^{3}$ modes, the resolution of Q1 was set to "low", so that all isotopes of a particular precursor were transmitted. For $\mathrm{MS}^{3}$ operation the excitation coefficient (slightly mass dependent) was set at a value to excite only the first and part of the second isotope. In the enhanced resolution mode the LIT was scanning at 250 $\mathrm{Da} / \mathrm{s}$ and the ion of interest was selected in Q1. Charge state determination up to four was possible. Data were acquired during 2 and $70 \mathrm{~min}$ for off-line and LC experiments, respectively. The needle voltage was set at $1000 \mathrm{~V}$ when measuring off-line and at $1800 \mathrm{~V}$ in an 
LC/MS experiment. Nitrogen was used as curtain (value of 20) and collision gas (set to high). Nebulizer and heater gas were both set to zero. The declustering potential was at $35 \mathrm{~V}$ to minimize in-source fragmentation. In precursor ion scanning the generation of a 204 Da fragment $\left(\mathrm{HexNAc}^{+}\right.$) was monitored. Both Q1 and Q3 resolution were set to "low" to increase sensitivity. Collision gas was at a value of 7 and collision energy was set between 25 and $50 \mathrm{eV}$. The spray needles used for all off-line experiments were Protana (Odense, DK) medium nanospray needles. Typically, $5 \mu$ l of sample was introduced.

For nano-LC/MS experiments a commercial HPLC system, i.e., an Ultimate Micro LC system combined with a FAMOS autosampler (LC-Packings, Amsterdam, The Netherlands) was used. The pump is of the classic reciprocal type, used at $150 \mu \mathrm{l} / \mathrm{min}$. It has a built-in flow splitting system to reduce the flow-rate to 100 $\mathrm{nl} / \mathrm{min}$. The samples $(4 \mu \mathrm{l})$ were loaded onto the column $(15 \mathrm{~cm} \times 75 \mu \mathrm{m}$ i.d. PEPMAP, C18, $3 \mu \mathrm{m}$ from LC-Packings) using an on-line preconcentration step on a micro precolumn $(2 \mathrm{~mm} \times 800 \mu \mathrm{m})$ cartridge. This was proven to be an essential step for both reducing sample loading times and desalting. The washing step was performed using $0.1 \%$ formic acid delivered at 10 $\mu \mathrm{l} / \mathrm{min}$ by a $130 \mathrm{~A}$ syringe pump (Applied Biosystems, Foster City, CA). After $10 \mathrm{~min}$, Valve A was switched to connect the precolumn to the separating column and the gradient was started. A linear gradient from 5\% acetonitrile $/ 0.1 \%$ formic acid to $80 \%$ acetonitrile $/ 0.1 \%$ formic acid, over a period of $50 \mathrm{~min}$, was applied. The column was connected to the UV detector equipped with a U-shaped cell and then linked directly via a 25 $\mu \mathrm{m}$ i.d. fused silica capillary to a nano-LC electrospray device, developed in the laboratory using PTFE sleeves. This device holds a New Objective PicoTip needle (Woburn, MA) with a $10 \mu \mathrm{m}$ tip. Data were acquired using IDA. Two different IDA experiments were performed: (1) An enhanced MS scan as survey scan, followed by an enhanced resolution scan of the two most intense ions, and an enhanced product ion scan of these ions if their charge state was 2 or 3 (total cycle time with two scans summed $\sim 4 \mathrm{~s}$ ); (2) a precursor ion scan as survey scan, followed by an enhanced resolution scan of the most intense ion, and an enhanced product ion scan of this ion if the charge state was 2 or 3 (total cycle time with two scans summed $\sim 5 \mathrm{~s}$, precursor ion scan was $3 \mathrm{~s}$ ). The collision energy was automatically adjusted based upon the ion charge state and mass. If an ion was detected twice in an enhanced resolution scan it was automatically excluded during $300 \mathrm{~s}$ so as to obtain as much information as possible.

\section{Results and Discussion}

The nomenclature describing the fragmentation of carbohydrates is that introduced by Domon and Costello [24]. Ions that retain the charge at the reducing terminus are designated $\mathrm{X}$ (cross-ring), $\mathrm{Y}$ and $\mathrm{Z}$ (glycosidic), whereas ions with the charge at the non-reducing terminus are designated A (cross-ring), B and C (glycosidic). The subscript numbers denote the position of the cleavage, and the superscript numbers associated with the cross-ring fragments show the bonds in the ring that are broken. Glycosidic cleavages provide information on sequence and branching. Cross-ring cleavages often reveal linkage, and also branching. The type of precursor ion produced from the carbohydrate has a significant effect on fragmentation. Protonated species decompose much more readily than metal-cationized species. The type of fragmentation produced by the various adducts also varies. Many more cross-ring cleavages are produced from metal-containing ions [10].

\section{Maltoheptaose}

Maltoheptaose, a linear glucose oligomer containing only $\alpha 1-4$ links (Figure 1a), provides a simple model for initial investigation of the features of the linear ion trap. Figure $1 \mathrm{~b}$ shows the MS/MS spectrum of a $5 \mathrm{pmol} / \mu \mathrm{l}$ solution. The single charged sodium-adduct precursor ion $(m / z 1175.4)$ was selected by the first quadrupole and accelerated into the pressurized $\left(\mathrm{N}_{2}\right)$ second quadrupole. The fragments and residual precursor ions were trapped in the third quadrupole (LIT) and scanned. This scan mode is called "enhanced product ion scanning" (scan modes using Q3 as LIT are called "enhanced scan modes"). In contrast to a conventional ion trap, the complete fragmentation pattern can already be seen in MS/MS. Glycosidic cleavages dominate the spectrum. The Y-C and the Z-B ions cannot be differentiated because of the symmetrical nature of the molecule. However, when performing MS/MS on maltoheptaose derivatized with 2-aminobenzoic acid or 3-aminopyrazole, almost no $\mathrm{C}$ and $\mathrm{Z}$ ions were observed (neither in positive nor in negative ion mode-data not shown). It is possible that these ions are also minor in the MS/MS spectrum of underivatized maltoheptaose. The main advantage of derivatisation at the reducing terminus is that fragment ions can be assigned unambiguously. Moreover, underivatized sugars frequently give fragment ions that are derived from multiple cleavages that cannot be attributed to a unique structure. Cross-ring cleavages are also present in the spectrum. The ${ }^{0,2} \mathrm{~A}$ $\left({ }^{0,4} \mathrm{~A},{ }^{1,3} \mathrm{~A}\right)$ and ${ }^{2,4} \mathrm{~A}$ are the most abundant cross-ring cleavages but, when magnifying the low intensity region of the spectrum, ${ }^{0,3} \mathrm{~A},{ }^{1,5} \mathrm{~A},{ }^{1,5} \mathrm{X}$ and ${ }^{3,5} \mathrm{~A}$ cleavages can also be seen. The isobaric $X$ cleavages cannot be ruled out.

The double charged sodium-adduct $[\mathrm{M}+2 \mathrm{Na}]^{2+}$ $(m / z$ 599.4) showed exactly the same fragmentation pattern as the single charged sodium adduct. No double charged fragments were present. A fragmentation spectrum of equal quality could now be obtained at lower collision energy. The $[\mathrm{M}+\mathrm{H}+\mathrm{Na}]^{2+}$ precursor $(\mathrm{m} / \mathrm{z}$ 588.3) gave rise to double and single charged fragments and fragmentation already took place at very low collision energy $(15 \mathrm{eV})$. Almost no cross-ring cleavages 

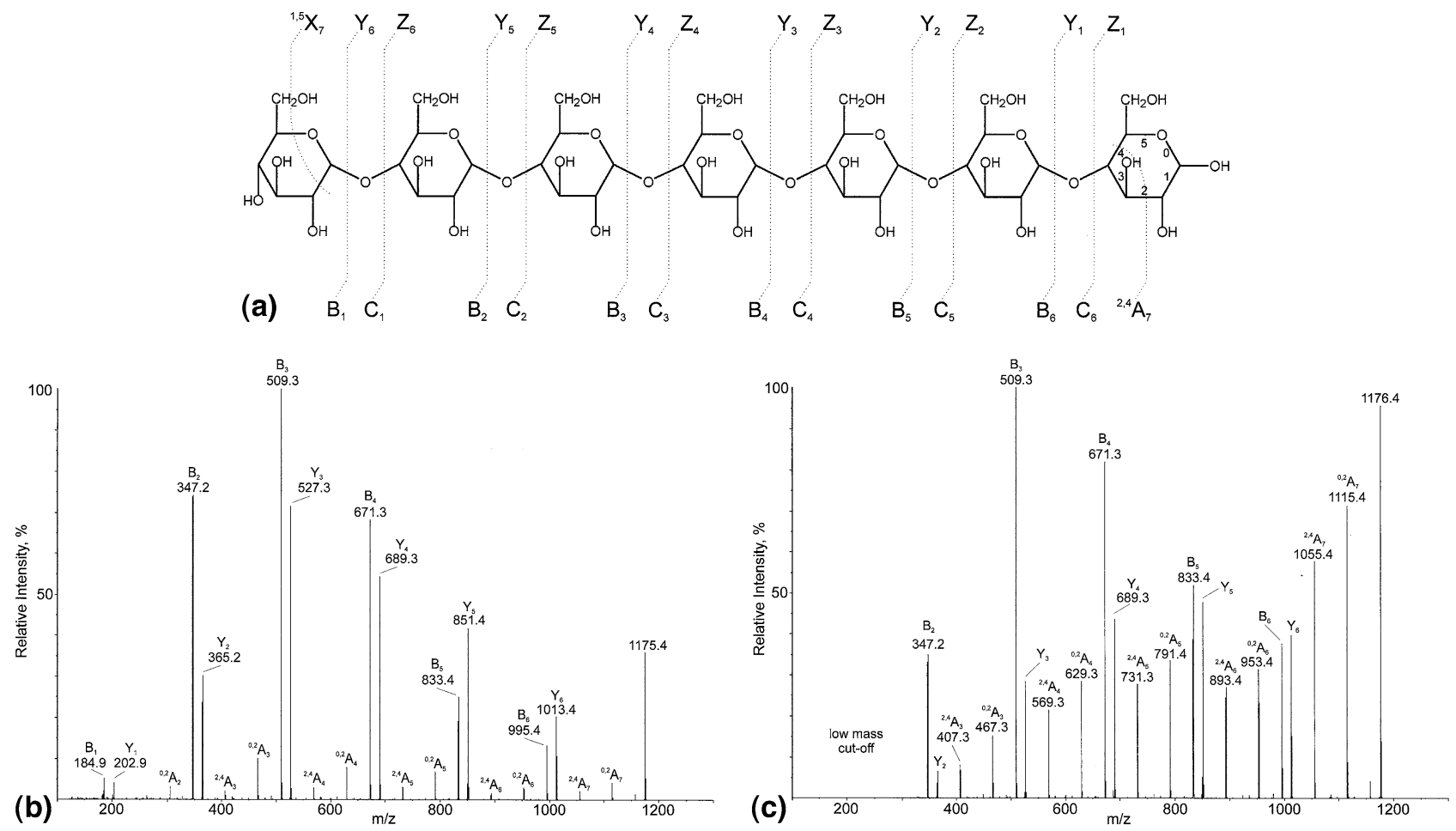

Figure 1. Structure of maltoheptaose and nomenclature for describing the fragmentation (a). MS/MS spectrum of single charged sodiated maltoheptaose at $m / z$ 1175.4: Fragmentation in Q2 with collision energy at $120 \mathrm{eV}(\mathbf{b})$, fragmentation in the LIT with collision energy at $10 \mathrm{eV}$ and excitation energy at 180 (c). In the LIT, the second isotope of the precursor ion is not excited to the same extent as the first, which explains the abundance of that isotope.

occurred. The $[\mathrm{M}+\mathrm{H}+\mathrm{K}]^{2+}$ ion resulted almost exclusively in double charged fragments, and again minor cross-ring cleavages could be seen. At a concentration of $50 \mathrm{fmol} / \mu \mathrm{l}$ of underivatized maltoheptaose, useful MS/MS information from the single charged sodium-adduct could still be obtained, demonstrating the sensitivity of the system in combination with nanospray.

MS/MS can also be performed in the linear ion trap. Minor collision energy $(10 \mathrm{eV})$ is then applied in the second quadrupole so that the precursor ion is transported to the LIT without fragmentation. This ion is then excited, fragmented and scanned out of the LIT. The spectrum of the single charged sodium-adduct is shown in Figure 1c. The cross-ring cleavages $\left({ }^{0,2} \mathrm{~A}\right.$ and ${ }^{2,4} \mathrm{~A}$ ions) are now much more prominent. Again the other cross-ring cleavage fragments are observed in the lower intensity region. As in conventional ion trap instruments, a low mass cut-off is present. This typical feature of the ion trap is also noticed when performing $\mathrm{MS}^{3}$ in the LIT. Figure 2a shows the $\mathrm{MS}^{3}$ spectrum of the ${ }^{0,2} \mathrm{~A}_{7}$ ion. In this scan mode, a particular fragment ion produced in the second quadrupole can be selected for a next stage of fragmentation in the third quadrupole. The $\mathrm{Y}$ ions as seen in Figure 1 are no longer present. The ${ }^{0,2} \mathrm{~A}_{6-3}$ ions can also correspond to ${ }^{0,2} \mathrm{~A}_{7} /$ $\mathrm{Y}_{6-3}$ ions and the $\mathrm{B}_{5-2}$ ions can also correspond to $\mathrm{B}_{6} / \mathrm{Y}_{6-3}$ ions. It is likely that different fragmentation pathways are present. Figure $2 \mathrm{~b}$ shows the $\mathrm{MS}^{3}$ spectrum of the $\mathrm{B}_{6}$ ion. All fragments correspond to $\mathrm{B}$ ions or $\mathrm{B}_{6} / \mathrm{Y}_{6-3}$ ions.

\section{RNase B Man ${ }_{5} \mathrm{GlcNAc}_{2}$}

The structure of the RNase B Man ${ }_{5} \mathrm{GlcNAc}_{2} \mathrm{~N}$-glycan is presented in Figure 3a. The branched nature and the presence of different linkages make it an interesting molecule to evaluate the features of the Q-Trap for carbohydrate characterization. The MS/MS spectrum of the underivatized single charged sodium-adduct $(\mathrm{m} / \mathrm{z}$ 1257.4) is shown in Figure 3b. The most dominant ions are those that arise from glycosidic cleavages. It appears that the loss of GlcNAc is very favorable. $\mathrm{C}$ and $\mathrm{Z}$ ions are also observed. They can be differentiated from the $Y$ and $B$ ions, without derivatization, because of the asymmetrical nature of the molecule. The sequence can most easily be determined when considering the B ions $(\mathrm{m} / \mathrm{z} 1036.4,833.2,671.2,509.2,347.1,185.1)$. At this stage it is impossible to demonstrate the existence of a branched structure. Many interesting cross-ring cleavage ions are present. The ${ }^{0,2} \mathrm{~A}_{4-5}$ and the ${ }^{2,4} \mathrm{~A}_{4-5}$ ions indicate 1-4 linkages of the GlcNAc residues. The ${ }^{2,4} \mathrm{~A}_{4-5}$ ions differ $1 \mathrm{Da}$ only from the $\mathrm{Y}$ ions at $\mathrm{m} / \mathrm{z}$ 1095.3 and 892.3. Looking into it in more detail, one can easily conclude that the intensity for these ions is too high to arise from the second isotope of the $\mathrm{Y}$ ions (see 

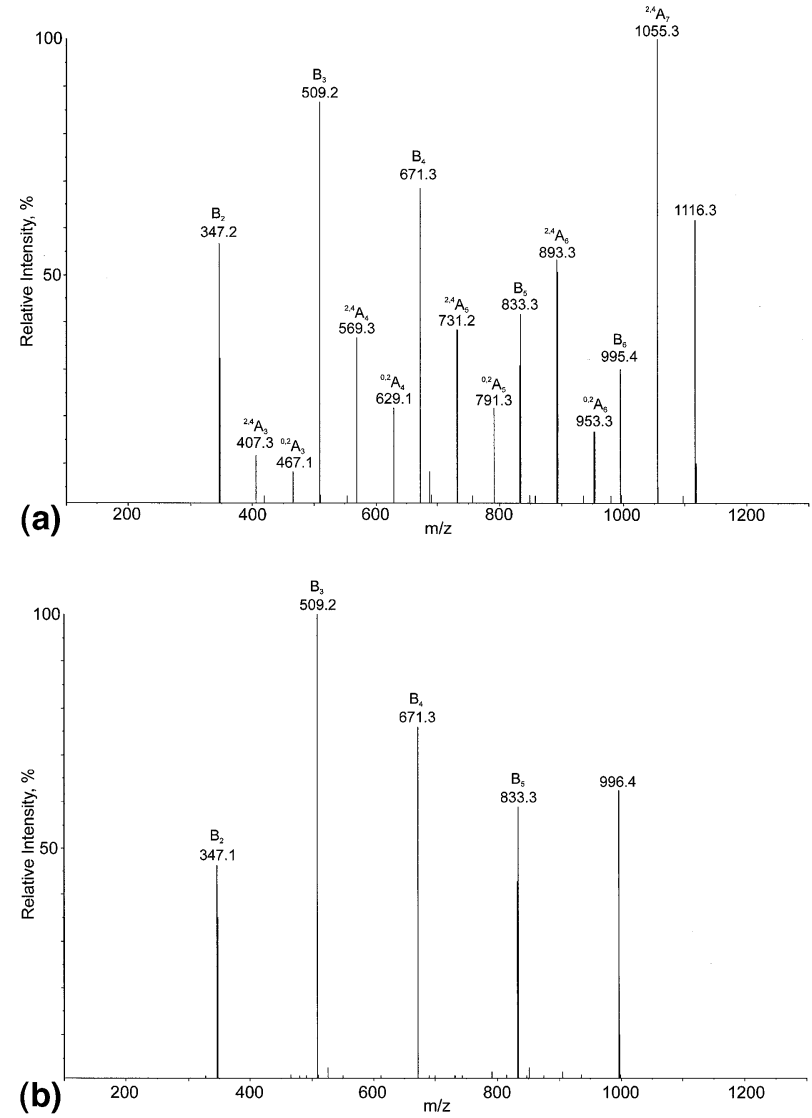

Figure 2. $\mathrm{MS}^{3}$ spectrum of the maltoheptaose ${ }^{0,2} \mathrm{~A}_{7}$ ion at $\mathrm{m} / \mathrm{z}$ $1115.4(\mathbf{a})$, and of the $\mathbf{B}_{6}$ ion at $\mathrm{m} / z$ 995.4 (b). The collision energy was set at $100 \mathrm{eV}$ and the excitation energy at 100 .

Figure 3c). The existence of the ${ }^{2,4} \mathrm{~A} 4$ ion $(\mathrm{m} / \mathrm{z}$ 893.3) can also be demonstrated when using $\mathrm{MS}^{3}$. The $\mathrm{B}_{4}$ ion $(\mathrm{m} / \mathrm{z}$ 1036.4) can never give rise to the $Y$ ion at $m / z 892.3$ (this ion has lost two terminal hexoses). Indeed, when performing $\mathrm{MS}^{3}$ on the $\mathrm{B}_{4}$ ion (Figure $4 \mathrm{a}$ ), no ion at $\mathrm{m} / \mathrm{z}$ 892.3 was present. However, an ion at $\mathrm{m} / \mathrm{z} 893.3$ is detected, revealing the existence of the ${ }^{2,4} \mathrm{~A}_{4}$ ion. The ${ }^{0,3} \mathrm{~A}_{3},{ }^{0,4} \mathrm{~A}_{3}$, and ${ }^{3,5} \mathrm{~A}_{3}$ ions are very informative because they indicate a linkage of a trihexose at carbon 6 of a hexose. Because there are five hexoses $\left(B_{3}\right.$ ion) present, and no ${ }^{0,3} \mathrm{~A}_{3}+162 \mathrm{Da}$ ion, there must be branching, possibly at the carbon atoms 2 or 3 . When the structure is not methylated, minor information can be extracted on branching from the cross-ring cleavages. When performing MS/MS in the LIT, less fragments are generated (data not shown). It is remarkable that the ${ }^{2,4} \mathrm{~A}_{4-5}$ $(\mathrm{m} / \mathrm{z} 893.3$ and 1096.3) ions dominate the $\mathrm{Y}$ ions $(\mathrm{m} / \mathrm{z}$ 892.3 and 1095.3), in contrast to the MS/MS spectrum obtained when performing fragmentation in Q2. $\mathrm{MS}^{3}$ fragmentation of the $B_{3}$ ion (Figure $4 b$ ) shows the usefulness of this higher order fragmentation since several peaks that were ignored (due to overlap with isotopes from abundant glycosidic fragments) or even absent in the MS/MS spectrum, can now be observed. For example, the presence of an $\mathrm{X}$ ion at $\mathrm{m} / \mathrm{z} 713.2$ could not be demonstrated in MS/MS because of the overlap with the second isotope of the $\mathrm{m} / \mathrm{z} 712.3$ ion $\left(\mathrm{C}_{3} /\right.$ $\left.\mathrm{Y}_{3 \beta}, \mathrm{Y}_{4 \alpha}, \mathrm{Y}_{4 \beta}\right)$. Because this ion cannot originate from the $\mathrm{B}_{3}$ ion, the ion at $m / z 713.2$ becomes clear. The absence of the ion at $m / z 550.3\left(\mathrm{~B}_{4} / \mathrm{Y}_{3 \beta} / \mathrm{Y}_{4 \alpha} / \mathrm{Y}_{4 \beta}\right)$ also reveals the existence of the $\mathrm{X}$ ion at $\mathrm{m} / \mathrm{z}$ 551.2. The $\mathrm{MS}^{3}$ spectrum of the ion at $m / z 671.2$ (Figure $4 \mathrm{c}$ ) is very similar to the $\mathrm{MS}^{3}$ spectrum of the $\mathrm{B}_{3}$ ion. However, three new fragments are observed $(\mathrm{m} / \mathrm{z} 625,463$, and 301). According to Harvey [25], the 625 ion can only originate from the $\mathrm{B}_{3} / \mathrm{Y}_{3 \mathrm{~b}}$ ion and the structure corresponds to an ${ }^{1,5} \mathrm{~A}_{3}$ ion that has lost a hydroxyl group at carbon 3 . The other ions $(\mathrm{m} / \mathrm{z} 463$ and 301) have lost additional terminal hexoses.

Although useful structural information was obtained for underivatized $\mathrm{Man}_{5} \mathrm{GlcNAc}_{2}$, it is much more convenient to study the methylated molecule (e.g., only branching at one point could be demonstrated). Methylation enables the determination of branching since only unoccupied linkage sites are methylated. The extent of methylation is inversely related to the degree of branching. If branching is present this should be reflected in the $Y$ ions. The branching point gives rise to an $\mathrm{Y}$ ion minus $x$ times $14 \mathrm{Da}$, where $x$ represents the number of branches. Methylation also aids in linkage determination. Depending on linkage position, different cross-ring fragments should be observed; 2-linkages would give rise to $\mathrm{A}$ ions that are equal to $\mathrm{B}$ ions +74 $\mathrm{Da}$; 4-linkages to $\mathrm{A}$ ions equal to $\mathrm{B}+88 \mathrm{Da}$ and 6-linkages to $\mathrm{A}$ ions equal to $\mathrm{B}+60$ and $88 \mathrm{Da}$. The MS/MS spectrum of methylated $\mathrm{Man}_{5} \mathrm{GlcNAc}_{2}$ is presented in Figure 5. The double charged sodium-adduct was selected for fragmentation $(\mathrm{m} / \mathrm{z}$ 801.4). Branching information is already obtained from the glycosidic fragments that contain the reducing terminus ( $\mathrm{Y}$ ions: $m / z$ 1361.7, 1143.5, 953.4, 735.3, 545.3, 300.1). After losing twice $218 \mathrm{Da}$ (terminal methylated hexose), a loss of 190 Da is detected. This means that branching exists at two points [218 Da minus 2(14), see before]. A further loss of 218 Da followed by a loss of 190 Da reveals another branching at two points. Other ions can also be used to demonstrate the branching pattern. Because of the complexity of the MS/MS spectrum it may be useful to study branching in an $\mathrm{MS}^{3}$ experiment. The $\mathrm{MS}^{3}$ spectrum of the $B_{3}$ ion is shown in Figure 6 . The ion at $m / z 431.1\left(B_{3} / Y_{3 \alpha}\right)$ indicates the loss of a trihexose that is branched at two points. A minor ion at $\mathrm{m} / \mathrm{z}$ 403.3 indicates a third loss of $218 \mathrm{Da}$ from the $\mathrm{B}_{3}$ ion. This demonstrates the presence of a second branching point. This $\mathrm{MS}^{3}$ spectrum was also used for another purpose. In the MS/MS spectrum, an ion at $\mathrm{m} / z 709.3$ is detected. This fragment corresponds with the ${ }^{3,5} \mathrm{~A}_{4}$ ion that has lost two terminal hexoses. However, it can also correspond with the very informative ${ }^{0,4} \mathrm{~A}_{3}$ ion. The $\mathrm{B}_{3}$ ion can never give rise to ${ }^{3,5} \mathrm{~A}_{4}$ ions, so $\mathrm{MS}^{3}$ of the $\mathrm{B}_{3}$ ion can demonstrate the existence of the ${ }^{0,4} \mathrm{~A}_{3}$ ion, and, indeed, the 709.3 ion is detected. This ion indicates that a branched trihexose $\left(B_{2 \alpha}\right)$ is attached to carbon 6 of another monosaccharide $\left(\mathrm{B}_{2 \alpha}+\right.$ $60 \mathrm{Da})$. There are also other useful cross-ring cleavage 

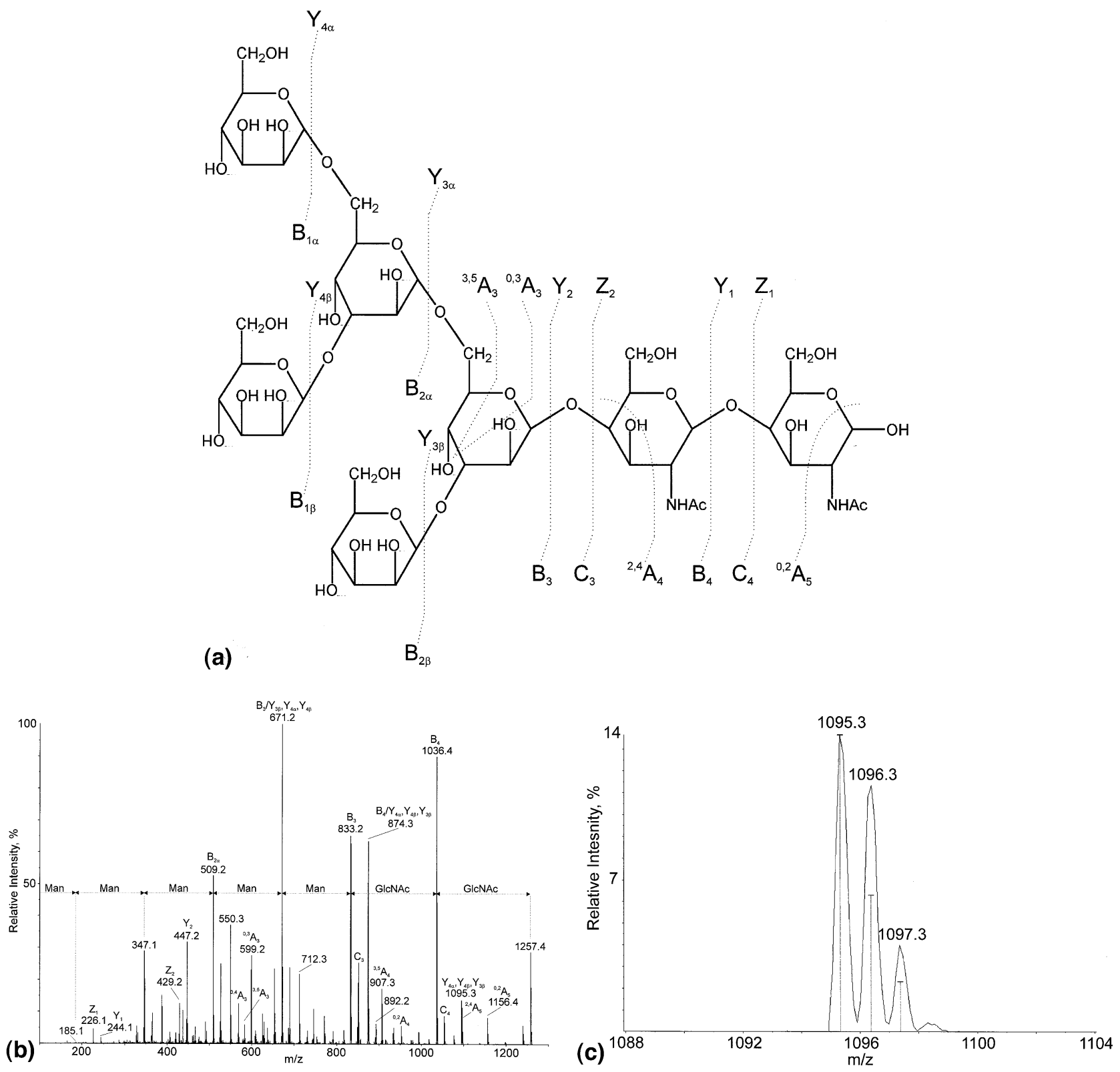

Figure 3. Structure of the RNase B Man ${ }_{5} \mathrm{GlCNAc}_{2} \mathrm{~N}$-glycan and fragmentation nomenclature (a). MS/MS spectrum of the single charged $\mathrm{Man}_{5} \mathrm{GlcNAc}_{2}$ sodium-adduct $(\mathrm{m} / \mathrm{z} 1257.4)$ obtained at a collision energy of $120 \mathrm{eV}(\mathbf{b})$. The inset shows the ion at $\mathrm{m} / \mathrm{z} 1095.3$ is shown in more detail (c). The lines present the theoretical isotope profile of the $\mathrm{Y}_{4 \alpha, 4 \beta, 3 \beta}$ ion.

ions. The ions at $m / z 301.0$ and $329.0\left({ }^{0,4} \mathrm{~A}_{2}\right.$ and $\left.{ }^{3,5} \mathrm{~A}_{2}\right)$ indicate the attachment of a terminal hexose (can only be the $\mathrm{B}_{1 \alpha}$ ion) to a carbon $6\left(\mathrm{~B}_{1 \alpha}+60\right.$ and $\left.88 \mathrm{Da}\right)$. In the MS/MS spectrum, the ion at $\mathrm{m} / \mathrm{z} 301.0$ was ignored because of the presence of the $Y_{1}$ ion at $\mathrm{m} / \mathrm{z}$ 300.1. However, this ion can not be formed from the $\mathrm{B}_{3}$ ion. The importance of the $\mathrm{MS}^{3}$ capabilities of the system is hereby stated once more. From the MS/MS spectrum it can further be deduced that the $\mathrm{B}_{3}$ ion is attached to the carbon 4 of the $\mathrm{GlcNAc}_{2}$ residue (see ${ }^{3,5} \mathrm{~A}_{4}$ ion). The internal GlcNAc residue is linked at the carbon 4 of the reducing GlcNAc residue $\left({ }^{3,5} \mathrm{~A}_{5}\right.$ ion).

\section{CBH I N-Glycans}

A typical glycan pool may contain both charged and uncharged glycans. Cellobiohydrolase I (CBH I), a major secretory protein from the fungus Trichoderma reesei, contains both neutral and phosphorylated highmannose $\mathrm{N}$-glycans [Stals, I. et al., unpublished]. Figure 7a presents the proposed structure of a phosphorylated $\mathrm{N}$-glycan liberated from the glycoprotein with Endo $\mathrm{H}$.

The MS/MS spectrum, recorded in the negative ion mode, is presented in Figure $7 \mathrm{~b}$. Only the fragments containing the phosphate group are detected and a lot 

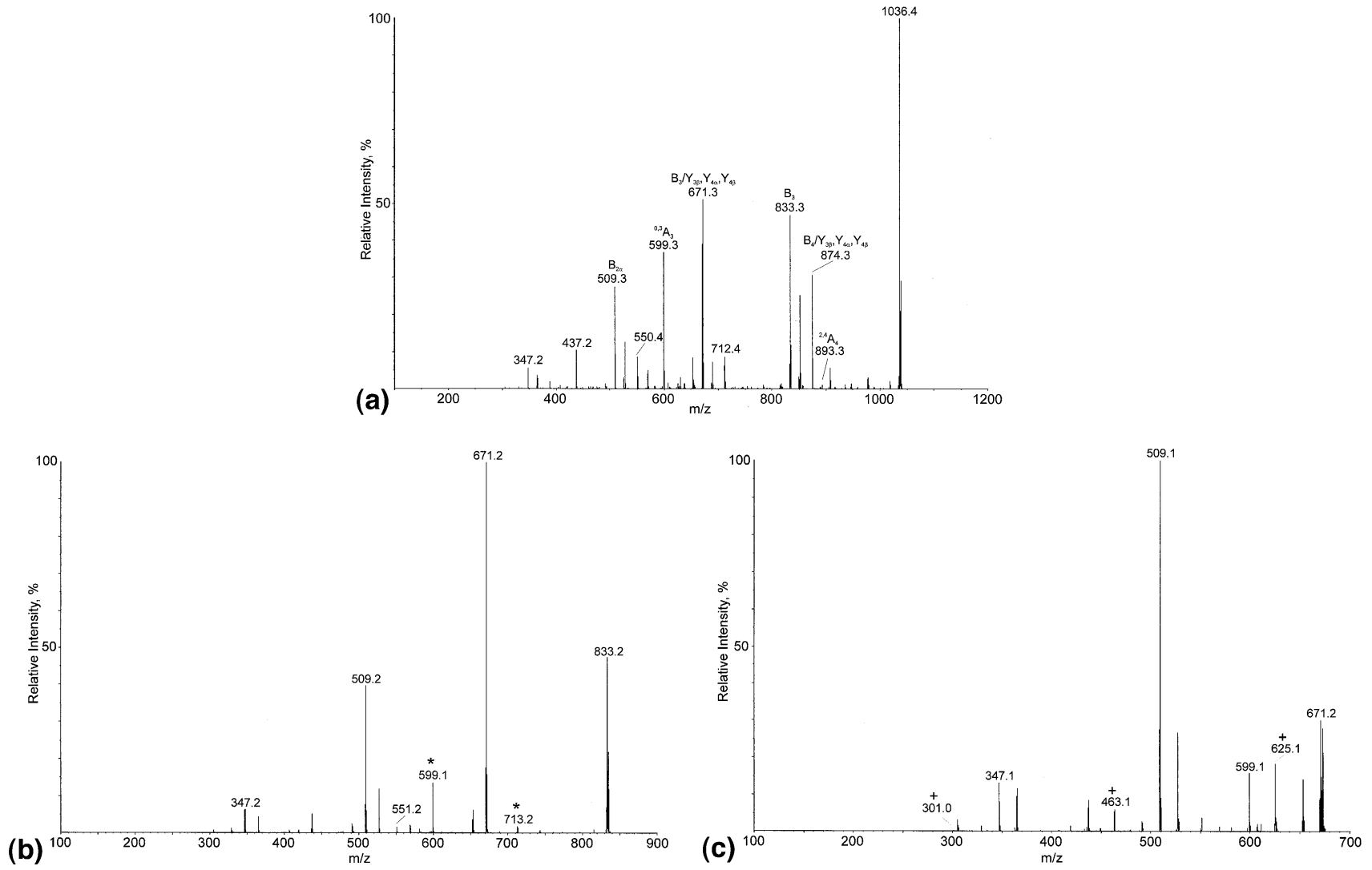

Figure 4. $\mathrm{MS}^{3}$ spectrum of the $\mathrm{Man}_{5} \mathrm{GlcNAc}_{2} \mathrm{~B}_{4}$ ion at $m / z 1036.4(\mathbf{a})$, the $\mathrm{B}_{3}$ ion at $m / z 833.2(\mathbf{b})$, and the ion at $\mathrm{m} / \mathrm{z} 671.2$ (c). The collision energy was set at $120 \mathrm{eV}$ and the excitation energy at 100 . The $X$ ions that are revealed upon $\mathrm{MS}^{3}$ of the $\mathrm{B}_{3}$ ion are marked with asterisks (spectrum $\mathrm{b}$ ). The new fragments in spectrum c (in comparison to spectrum b) are marked with a cross.

of useful information seems to be lost. The presence of an internal phosphate residue (phosphodiester bond) cannot be proven from the spectrum. However, when labeling the reducing terminus with a negatively charged tag the existence of such a structure can be demonstrated. The MS/MS spectrum of the glycan derivatized with 2-aminobenzoic acid is presented in Figure 7c. The double charged ion $[\mathrm{M}-2 \mathrm{H}]^{2-}(\mathrm{m} / \mathrm{z}$

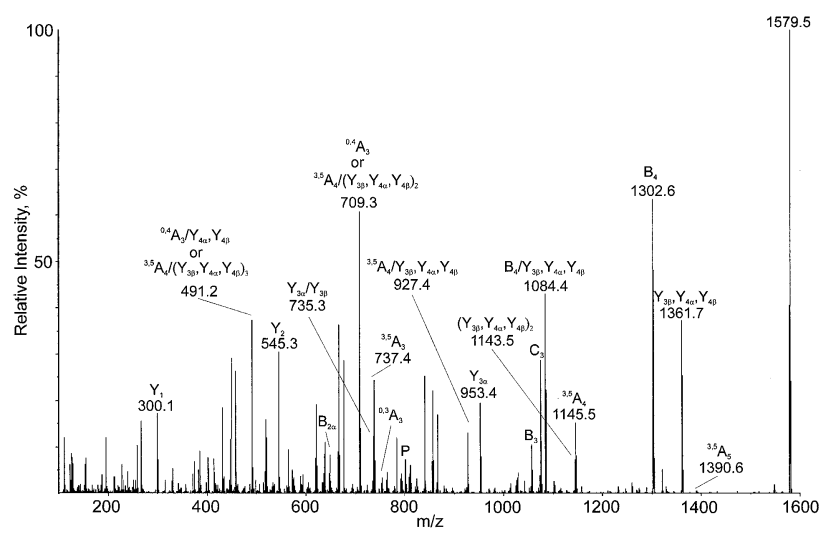

Figure 5. MS/MS spectrum of methylated $\mathrm{Man}_{5} \mathrm{GlcNAc}_{2}$ (double charged sodium-adduct at $m / z$ 801.4, P: precursor) obtained at a collision energy of $70 \mathrm{eV}$.
696.1) was selected for fragmentation. The fragment ions that have lost the phosphate moiety can now be detected (as single charged ions). The ion at $\mathrm{m} / \mathrm{z} 615.1$ corresponds to the double charged $Y_{5}$ ion. The formation of a $Y_{3 \beta}$ or $Y_{2 \beta}$ fragment is very unlikely because a hexose linked to a phosphate is much more labile than a glycosidic bond. The loss of a phosphate results in the intense (and thus stable) single charged ion at $\mathrm{m} / \mathrm{z}$

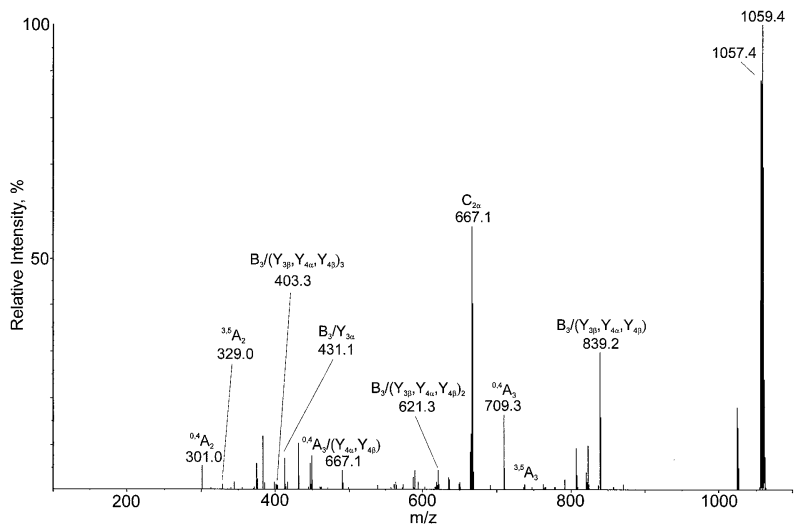

Figure 6. $\mathrm{MS}^{3}$ spectrum of the methylated $\mathrm{Man}_{5} \mathrm{GlcNAc}_{2} \mathrm{~B}_{3}$ ion $(\mathrm{m} / \mathrm{z}$ 1057.4). Collision energy was set at $70 \mathrm{eV}$ and excitation energy at 85 . 

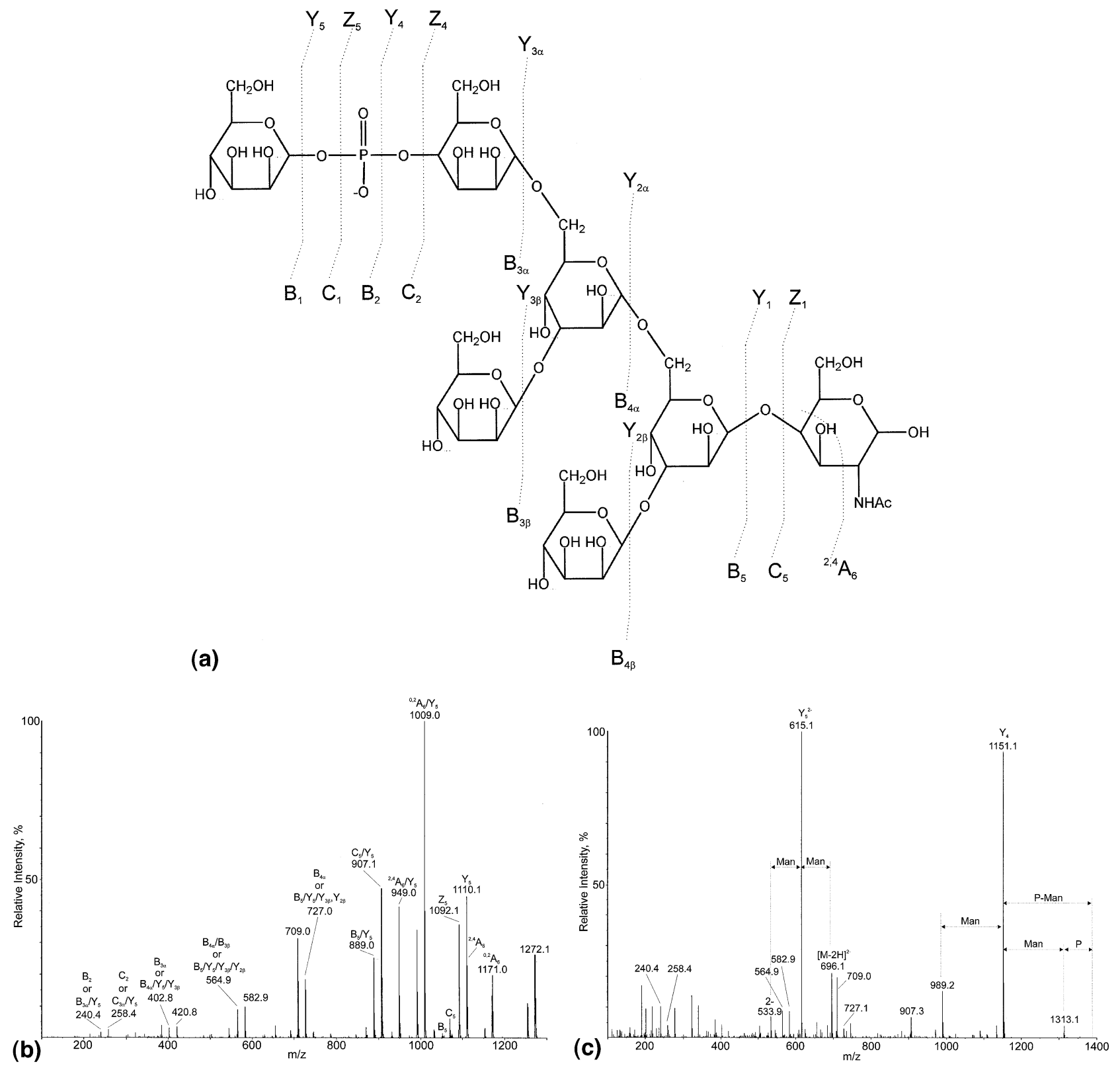

Figure 7. Structure of a phosphorylated $\mathrm{N}$-glycan (ManPMan ${ }_{5} \mathrm{GlcNAc}$ ) liberated from CBH I with Endo H (a). MS/MS spectrum of single charged $(\mathrm{m} / \mathrm{z}$ 1272.1) underivatized $(\mathbf{b})$ and double charged $(\mathrm{m} / \mathrm{z}$ 696.1) derivatized (c) phosphorylated $N$-glycan. The collision energy was -90 and $-50 \mathrm{eV}$ respectively.

$1151.1\left(\mathrm{Y}_{4}\right)$. Because the first loss is a hexose (162 Da) and the second a phosphate $(80 \mathrm{Da})$, the existence of an internal phosphate residue is proven. The ion at $\mathrm{m} / \mathrm{z}$ 1313.1 indicates the presence of an isobaric structure with a terminal phosphate. The $\mathrm{MS}^{3}$ spectrum of the double charged $Y_{5}$ ion is presented in Figure 8. The $Y_{4}$ ion dominates the spectrum (at very high excitation energy).

\section{Glycopeptides}

The study of protein glycosylation is much more challenging than oligosaccharide analysis. Determination of the glycosylation sites and the oligosaccharide heterogeneity at each site are at least as important. This information can only be obtained from the study of glycopeptides after enzymatic or chemical hydrolysis of the glycoprotein. Carr and co-workers [26] demonstrated that glycopeptides can be selectively detected in a proteolytic mixture by the appearance of marker oxonium ions such as $\mathrm{m} / z 163\left(\mathrm{Hex}^{+}\right), 204\left(\mathrm{HexNAc}^{+}\right)$, or $366\left(\mathrm{HexHexNAc}^{+}\right)$originating from collisionally excited glycopeptides. Such determinations are most easily performed on triple quadrupole instruments using precursor ion scanning. The third quadrupole is set to pass the oxonium ion of interest produced in the 


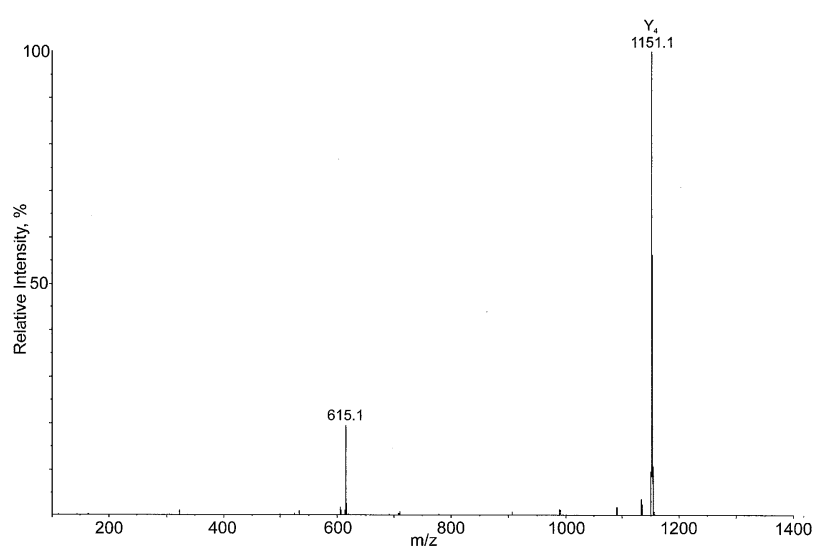

Figure 8. $\quad \mathrm{MS}^{3}$ spectrum of the double charged $\mathrm{Y}_{5}$ ion $(\mathrm{m} / \mathrm{z}$ 615.1) of the derivatized phosphorylated glycan. Collision energy was set at $-50 \mathrm{eV}$ and excitation energy at 180 .

collision region (second quadrupole) and the first quadrupole is scanned. Only those ions that fragment to produce the selected oxonium ion are detected. The Q-Trap system with its capabilities to perform typical triple quadrupole scans can also be used for this purpose. The precursor ion scan mode is not as sensitive as the scan modes using LIT, but its only purpose is to identify the glycopeptides which are then selected for MS/MS. Figure 9a shows the MS spectrum of an RNase $B$ tryptic digest using Q3 as LIT (enhanced MS, scan rate 4000). An overnight digestion of RNase B was needed to

(a)
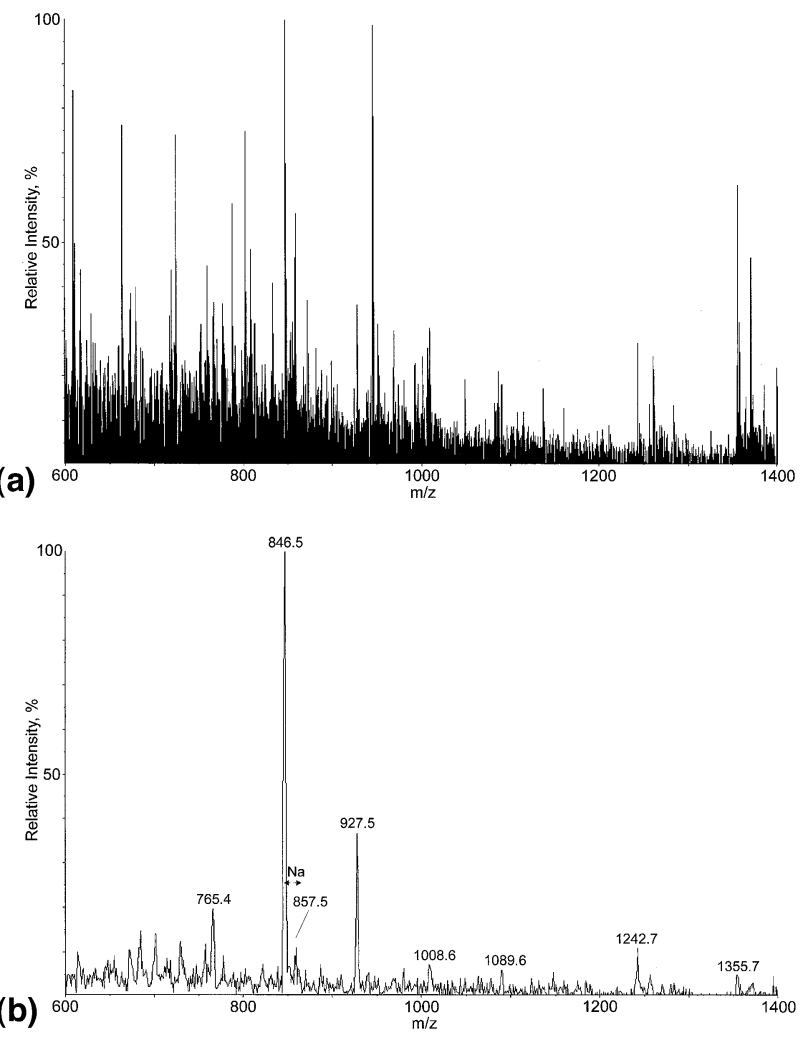

Figure 9. Enhanced MS (a) and precursor ion scan (monitoring $\mathrm{m} / \mathrm{z}$ 204) spectrum (b) of an unseparated RNase B tryptic digest.

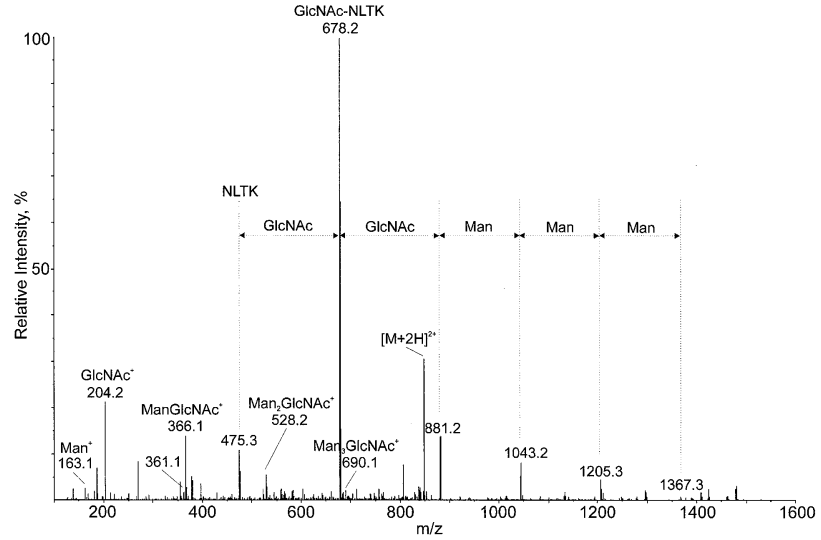

Figure 10. MS/MS spectrum of the double charged glycosylated RNase B peptide at $\mathrm{m} / \mathrm{z}$ 846.5. Collision energy was set at $35 \mathrm{eV}$.

obtain a sufficient peptide signal, although the protein was still detectable (see Figure 9a, $m / z$ 1200-1400). The precursor ion mass spectrum (monitoring $\mathrm{m} / \mathrm{z} 204$ ) of the digest is shown in Figure 9b. The peptide signal is diminished here. As shown in a recent paper [27], high resolution is required to be more specific when dealing with precursor ion scanning of complex digests. However, the authors showed that the HexNAc oxonium ion is remarkably specific, even in low resolution mode, in contrast to the Hex and HexHexNAc oxonium ions. The main ion, corresponding to a $\mathrm{Man}_{5} \mathrm{GlcNAc}_{2}$ structure attached to the tetrapeptide NLTK (double charged), was selected for MS/MS and the spectrum is shown in Figure 10. The spectrum is dominated by glycan fragmentation; however, peptide fragmentation becomes more dominant when the collision energy is increased. The abundant single charged fragment at $\mathrm{m} / \mathrm{z} 678.2$ corresponds to a GlcNAc linked to the peptide and the loss of this monosaccharide results in the ion at $\mathrm{m} / \mathrm{z}$ 475.3. The peaks at $m / z 765.4,927.5,1008.6$, and 1089.6 in the precursor ion spectrum correspond to $\mathrm{Man}_{4,6-8}$ Glc$\mathrm{Nac}_{2}$ structures attached to the same tetrapeptide (NLTK). The loss of the oxonium ion from the glycoprotein is also detected (see $\mathrm{m} / \mathrm{z} 1242.7$ and 1355.7).

The precursor ion scan mode can also be used as survey scan in an IDA experiment. This is typically useful in combination with LC/MS/MS. An enhanced resolution scan can then be included between precursor ion scanning and MS/MS to obtain the peptide charge state and to improve mass accuracy for proper precursor selection. This approach was performed on a CBH I tryptic digest. Figure 11 shows the LC/MS/MS total ion current (TIC) chromatogram of the precursor ion scan (monitoring $\mathrm{m} / \mathrm{z} 204$ ). The precusor ion scan at time 30.0 $\mathrm{min}$, the enhanced resolution scan of the most intense ion at that time, and the enhanced product ion scan of that peptide are presented in Figure 12. The peptide is $\mathrm{N}$-glycosylated with a single GlcNAc residue, and as a consequence, the peptide fragmentation is not suppressed by glycan fragmentation. The sequence can easily be elucidated from the $b$ and $y$ ions. The ions at 


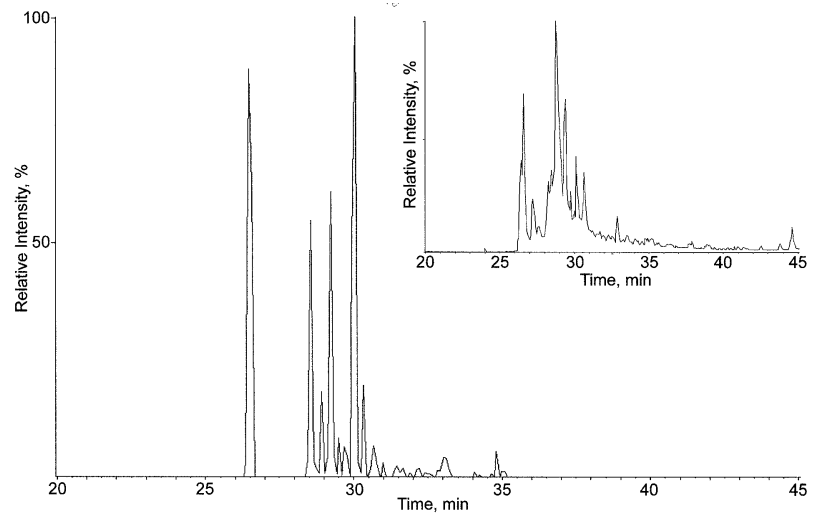

Figure 11. LC/MS/MS TIC chromatograms of a CBH I tryptic digest using an IDA experiment with precursor ion scanning and enhanced MS (inset) as survey scans.

$\mathrm{m} / \mathrm{z} 285.2$ and 488.3 correspond to the b3 ion (LGN) with and without the GlcNAc residue, respectively. The inset in Figure 11 shows the TIC chromatogram of an IDA experiment where the precursor ion scan, as survey scan, is replaced by an enhanced MS scan (scan rate $4000 \mathrm{Da} / \mathrm{s})$. In this way all the peptides are detected. An extra product ion scan has been included because the "time consuming" triple quadrupole scan function is replaced by a fast LIT scan. Now the two most intense peptides are selected for fragmentation when they pass the IDA criteria. This approach is presently applied for the identification of proteins from 2-D gel spots. All
MS/MS data obtained are then transferred to Mascot for an MS/MS ion search.

\section{Conclusion}

For carbohydrate chemists and glycobiologists, the QTrap represents a powerful new tool to study protein glycosylation at high sensitivity. At the oligosaccharide level MS/MS and MS $^{3}$ provides information on sequence, linkage and branching. Derivatisation procedures such as permethylation and reductive amination aid in structural elucidation. The complete fragmentation pattern is already shown in the MS/MS scan mode due to the triple quadrupole-like fragmentation and the absence of a low mass cut-off. The origin of fragments and the existence of new ions is revealed using $\mathrm{MS}^{3}$. There is no need for higher order $\mathrm{MS}^{n}(n>3)$ capabilities. The Q-Trap retains all the triple quadrupole scan modes. The precursor ion scan mode, which can be used as survey scan in an IDA experiment, is especially useful for the determination of the glycosylation sites and the occupancy at each site.

\section{Acknowledgments}

This work was supported by a research grant to KS from the Institute for the Promotion of Innovation by Science and Technology in Flanders (IWT-Vlaanderen) and by the Fund for Scientific Research-Flanders (FWO-Vlaanderen) through project G.0312.02 to JVB and BD. The authors gratefully acknowledge Frank Vanrobaeys for assisting with the LC analyses.
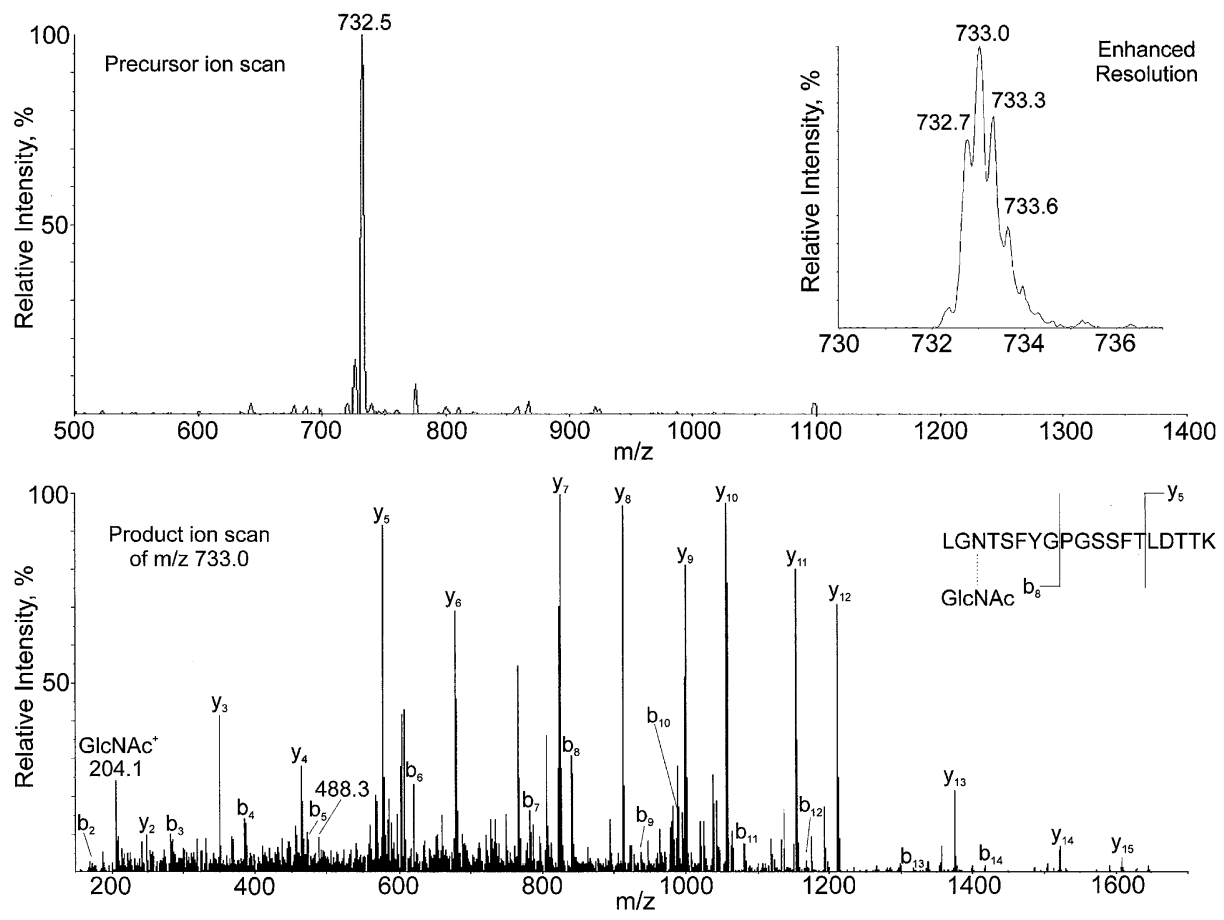

Figure 12. Precursor ion scan at $30.0 \mathrm{~min}$ (see Figure 11), enhanced resolution scan of the most intense ion at that time and enhanced product ion scan of that ion. The product ion scan was acquired using rolling collision energy and the charge state determined in the enhanced resolution scan and the mass were used to calculate the collision energy. 


\section{References}

1. Varki, A. Biological Roles of Oligosaccharides: All of the Theories are Correct. Glycobiol 1993, 3(2), 97-130.

2. Axford, J. The Impact of Glycobiology on Medicine. Trends Immunol. 2001, 22(5), 237-239.

3. Cumming, D. A. Glycosylation of Recombinant Protein Therapeutics: Control and Functional Implications. Glycobiol. 1991, 1, 115-130.

4. Harvey, D. J. Matrix-Assisted Laser Desorption/Ionization Mass Spectrometry of Carbohydrates and Glycoconjugates. Int. J. Mass Spectrom. 2003, 226, 1-35.

5. Harvey, D. J.; Naven, T. J. P.; Küster, B.; Bateman, R. H.; Green, M. R.; Critchley, G. Comparison of Fragmentation Modes for the Structural Determination of Complex Oligosaccharides Ionized by Matrix-Assisted Laser Desorption/Ionization Mass Spectrometry. Rapid Commun. Mass Spectrom. 1995, 9, 15561561.

6. Rouse, J. C.; Strang, A.; Yu, W.; Vath, J. E. Isomeric Differentation of Asparagines-Linked Oligosaccharides by MatrixAssisted Laser Desorption-Ionization Postsource Decay Timeof-Flight Mass Spectrometry. Anal. Biochem. 1998, 256, 33-46.

7. Harvey, D. J.; Bateman, R. H.; Green, M. R. High-Energy Collision-Induced Fragmentation of Complex Oligosaccharides Ionized by Matrix-Assisted Laser Desorption/Ionization Mass Spectrometry. J. Mass Spectrom. 1997, 32, 167-187.

8. Hanrahan, S.; Charlwood, J.; Tyldesley, R.; Langridge, J.; Bordoli, R.; Bateman, R.; Camilleri, P. Facile Sequencing of Oligosaccharides by Matrix-Assisted Laser Desorption/Ionization on a Hybrid Quadrupole Orthogonal Acceleration Time-of-Flight Mass Spectrometer. Rapid Commun. Mass Spectrom. 2001, 15, 1141-1151.

9. Reinhold, V. N.; Reinhold, B. B.; Costello, C. E. Carbohydrate Molecular Weight Profiling, Sequence, Linkage, and Branching Data: ES-MS and CID. Anal. Chem. 1995, 67, 1772-1784.

10. Harvey, D. J. Collision-Induced Fragmentation of Underivatized $N$-Linked Carbohydrates Ionized by Electrospray. J. Mass Spectrom. 2000, 35, 1178-1190.

11. Harvey, D. J. Ionization and Collision-Induced Fragmentation of $\mathrm{N}$-Linked and Related Carbohydrates Using Divalent Cations. J. Am. Soc. Mass Spectrom. 2001, 12, 926-937.

12. Wilm, M.; Mann, M. Analytical Properties of the Nanoelectrospray Ion Source. Anal. Chem. 1996, 68, 1-8.

13. Bahr, U.; Pfenninger, A.; Karas, M.; Stahl, B. High-Sensitivity Analysis of Neutral Underivatized Oligosaccharides by Nanoelectrospray Mass Spectrometry. Anal. Chem. 1997, 69, 45304535.

14. Weiskopf, A. S.; Vouros, P.; Harvey, D. J. Characterization of Oligosaccharide Composition and Structure by Quadrupole
Ion Trap Mass Spectrometry. Rapid Commun. Mass Spectrom. 1997, 11, 1493-1504.

15. Weiskopf, A. S.; Vouros, P.; Harvey, D. J. Electrospray Ionization-Ion Trap Mass Spectrometry for Structural Analysis of Complex $\mathrm{N}$-Linked Glycoprotein Oligosaccharides. Anal. Chem. 1998, 70, 4441-4447.

16. Sheeley, D. M.; Reinhold, V. N. Structural Characterization of Carbohydrate Sequence, Linkage, and Branching in a Quadrupole Ion Trap Mass Spectrometer: Neutral Oligosaccharides and N-Linked Glycans. Anal. Chem. 1998, 70, 3053-3059.

17. Creaser, C. S.; Reynolds, J. C.; Harvey, D. J. Structural Analysis of Oligosaccharides by Atmospheric Pressure Matrix-Assisted Laser Desorption/Ionization Quadrupole Ion Trap Mass Spectrometry. Rapid Commun. Mass Spectrom. 2002, 16, 176-184.

18. Hager, J. W. A New Linear Ion Trap Mass Spectrometer. Rapid Commun. Mass Spectrom. 2002, 16, 512-526.

19. Hager, J. W.; Le Blanc, J. C. Product Ion Scanning Using a Q-q- $\mathrm{Q}_{\text {linear ion trap }}(\mathrm{Q}$ TRAP) Mass Spectrometer. Rapid Commun. Mass Spectrom. 2003, 17, 1056-1064.

20. Jackson, P. In Methods in Enzymology; Lennarz, W. J.; Hart, G. W., Eds.; Academic Press, Inc: San Diego, CA, 1994; pp 253-257.

21. Packer, N. H.; Lawson, M. A.; Jardine, D. R.; Redmond, J. W. A General Approach to Desalting Oligosaccharides Released from Glycoproteins. Glycoconj. J. 1998, 15, 737-747.

22. Ciucanu, I.; Kerek, F. A Simple and Rapid Method for the Permethylation of Carbohydrates. Carbohydr. Res. 1984, 131, 209-217.

23. Evangelista, R. A.; Chen, F. T. A.; Guttman, A. Reductive Amination of $\mathrm{N}$-Linked Oligosaccharides Using Organic Acid Catalysts. J. Chromatogr. A 1996, 745, 273-280.

24. Domon, B.; Costello, C. E. A Systematic Nomenclature for Carbohydrate Fragmentations in FAB-MS/MS Spectra of Glycoconjugates. Glycoconj. J. 1988, 5(4), 397-409.

25. Harvey, D. J. Electrospray Mass Spectrometry and Fragmentation of $\mathrm{N}$-Linked Carbohydrates Derivatized at the Reducing Terminus. J. Am. Soc. Mass Spectrom. 2000, 11, 900-915.

26. Huddleston, M. J.; Bean, M. F.; Carr, S. A. Collisional Fragmentation of Glycopeptides by Electrospray Ionization LC/MS and LC/MS/MS: Methods for Selective Detection of Glycopeptides in Protein Digests. Anal. Chem. 1993, 65, 877884.

27. Jebanathirajah, J.; Steen, H.; Roepstorff, P. Using Optimized Collision Energies and High Resolution, High Accuracy Fragment Ion Selection to Improve Glycopeptide Detection by Precursor Ion Scanning. J. Am. Soc. Mass Spectrom. 2003, 14, 777-784. 